UDC 66.071.7.546.131

DOI: 10.15587/2706-5448.2021.225023

Article type «Reports on Research Projects»

\section{Yurii Beznosyk, Liudmyla Bugaieva}

\title{
STUDY OF STRUCTURE OF FLOWS OF A TECHNOLOGICAL APPARATUS USING THE THEORY OF RANDOM FUNCTIONS
}

The object of research is the structure of flows in the absorber of hydrogen chloride. One of the most problematic areas in the study of flow hydrodynamics in chemical-technological devices are both technological and technical difficulties, when the device is exposed to random disturbances and/or the supply of a standard indicator is impossible due to a violation of the technological regulations.

A method for studying the hydrodynamic structure of flows in a shelf absorber of hydrogen chloride of the «Korobon-KA» type (Germany) in the normal operation of a chemical apparatus using the theory of random functions is proposed. An industrial experiment was carried out on the operating equipment to determine the input and output concentrations of the components of the gas flow. The absorber of hydrogen chloride is considered as a one-dimensional object, at the input of which a random function acts - the concentration of hydrogen chloride in the input stream, and at the output there is a random variable - the concentration of hydrogen chloride in the output stream. The method for determining hydrogen chloride and chlorine in a gas stream is based on the absorption of chlorine by a solution of potassium iodide, followed by titration of the released iodine with sodium thiosulfate. In parallel, portions of acid were sampled at the inlet and outlet, and then the density and temperature of the hydrochloric acid solutions were determined.

An algorithm for calculating the impulse function estimates is developed. The obtained experimental data are smoothed. As a result of processing the experimental data, autocorrelation and cross-correlation functions were obtained, the Wiener-Hopf equation was solved, and the impulse weight function was obtained. Having calculated the moments of the obtained impulse weight function, it was proved that the structure of flows in the «Korobon-KA» absorber can be satisfactorily described by the ideal displacement model. The calculations were carried out in software environments MathCAD, Matlab.

According to the results obtained, the proposed method for determining the hydrodynamic structure of flows will find application in the study of chemical-technological devices, when the object is exposed to random disturbances and the supply of a standard indicator is impossible due to violation of technological regulations. This makes it possible to find the parameters of flow hydrodynamics in the apparatus in the mode of its normal operation.

Keywords: flow hydrodynamics, dynamic characteristics, autocorrelation function, cross-correlation function, Wiener-Hopf equation, distribution function.

\section{Introduction}

The mathematical model of a chemical-technological object is largely determined by its hydrodynamic parameters. One of these parameters is the distribution of the residence time of the flow particles in the apparatus, which can be obtained experimentally using the indicator method - the supply of standard signals to the apparatus input [1, 2]. However, in the study of the hydrodynamic characteristics of operating industrial devices, technical difficulties often arise. These can be both technological difficulties, when the supply of a standard indicator is impossible due to the lack of appropriate design units, and fundamental difficulties, when the object is exposed to random disturbances. In some cases, they may have both those and other difficulties. Under these conditions, to study the hydrodynamics of flows in an industrial apparatus, it is proposed to use the theory of random functions.

The problem of determining the dynamic characteristics in the normal operation of industrial facilities by the method of estimating correlation functions is widely used in the theory of automatic control and regulation and was developed in [3, 4].

When identifying dynamic objects, the sources of information are the input $X(t)$ and output $Y(t)$ signals of the object. An industrial facility is viewed as a system that converts an input signal into an output signal. In this case, the dynamic model of the object in general form can be described by the Wiener-Hopf integral equation [5, 6].

Integral equations of the Wiener-Hopf type [7] are widely used in chemical, petrochemical, food technologies. The use of methods of regression and correlation analysis for the 
processes of the food and chemical industry, based on multivariate data analysis, is given in the fundamental work [8].

Thus, in [5], a solution to the integral equation was obtained to find the distribution of the temperature flow in a tubular reactor for different boundary conditions. The use of the results of solving the Wiener-Hopf equation for controlling a fixed-bed reactor is presented in [9]. The preset temperature in the reactor is controlled by a controller programmed on the basis of models of multiparameter transfer functions. The models are developed using multiparameter time series and process identification methods. The optimal control solution was obtained by solving the spectral factorization for the Wiener-Hopf equations [9]. Statistical identification methods were used to analyze the operation of industrial wastewater treatment plants [10]. The developed dynamic mathematical model of the wastewater treatment plant is based on the characteristics of random input and output signals taken in real time. The setup transfer function was determined from the autocorrelation input function and the inputoutput cross-correlation function using the Wiener-Hopf integral equation.

However, the application of the theory of random functions to the study of the hydrodynamic structure of flows of chemical-technological objects is rare [11, 12], although this approach has serious advantages in the study of operating devices.

Therefore, experimental studies of the structure of hydrodynamic flows of technological devices in the mode of their normal operation are relevant. The object of research is the structure of flows in the absorber of hydrogen chloride, and the aim of research is to establish the structure of flows in the absorber using the theory of random functions.

\section{Methods of research}

The process of absorption of hydrogen chloride by water in a plate apparatus of the «Korobon-KA» type (Germany) [13] (Fig. 1) was studied.

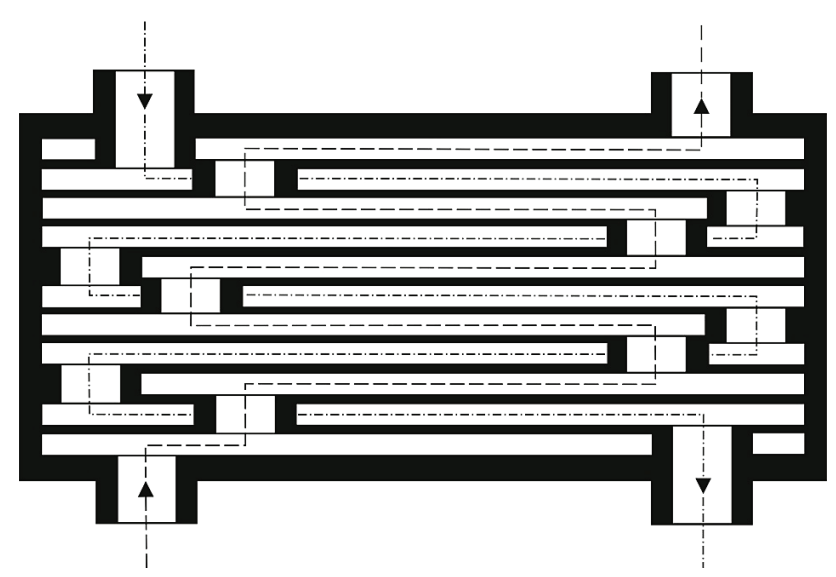

Fig. 1. Diagram of the Korobon-KA absorber

The absorber is considered as a one-dimensional object, at the input of which a random function $X(t)$ acts - the concentration of hydrogen chloride in the input stream, and at the output there is a random variable $Y(t)$ - the concentration of hydrogen chloride in the output stream. It is known [1, 4] that the hydrodynamics of an object is described by the impulse function $K(t)$, which is statisti- cally interpreted as the distribution density of the residence time of the flow particles in the apparatus [4, 14].

To study the hydrodynamic structure of flows in a graphite plate absorber, an experiment was carried out on an operating industrial installation. Since the object under study did not allow the introduction of artificial disturbances (due to the high chemical activity of the components of the gas-liquid flow and the danger of emergencies), the experiments were carried out in the normal operating mode of the apparatus. The objective of the experiment was to determine the content of hydrogen chloride and chlorine at the inlet and outlet of the apparatus, as well as to determine the concentration of hydrochloric acid supplied to the irrigation of the absorber and obtained as a result of absorption of hydrogen chloride.

The method for determining hydrogen chloride and chlorine in a gas stream is based on the absorption of chlorine by a solution of potassium iodide, followed by titration of the released iodine with sodium thiosulfate.

$$
\begin{aligned}
& \mathrm{Cl}_{2}+2 \mathrm{KJ}=\mathrm{J}_{2}+2 \mathrm{KCl}, \\
& \mathrm{J}_{2}+2 \mathrm{Na}_{2} \mathrm{~S}_{2} \mathrm{O}_{3}=\mathrm{Na}_{2} \mathrm{~S}_{4} \mathrm{O}_{4}+2 \mathrm{NaJ} .
\end{aligned}
$$

The operation of absorption of the taken samples of the reaction gas was carried out in a burette with a $5 \%$ solution of potassium iodide. The resulting solution was titrated with a $0.1 \mathrm{n} \cdot \mathrm{Na}_{2} \mathrm{~S}_{2} \mathrm{O}_{3}$ solution until discoloration. The chlorine content in the mixture was calculated using the following formula:

$$
x_{\mathrm{Cl}_{2}}=1.12 \mathrm{Ka} / \mathrm{V} \text {, }
$$

where $a$ - the number of $\mathrm{ml}$ of $0.1 \mathrm{n} \cdot \mathrm{Na}_{2} \mathrm{~S}_{2} \mathrm{O}_{3}$ solution, which was used for titration; $V$ - burette volume; $K$ correction factor.

The amount of hydrogen chloride in the mixture was determined as the difference between the total fraction of gases absorbed in the burette and the chlorine content in them:

$$
x_{\mathrm{HCl}}=\frac{V_{1}}{V}-x_{\mathrm{Cl}_{2}} \text {, }
$$

here $V_{1}$ - total volume of gases absorbed in the burette.

Samples were taken every $\Delta t=90 \mathrm{~s}$. The range of operating flow rates of the reaction gas was within $0.10-0.13 \mathrm{~nm}^{3} / \mathrm{s}$, the flow rate of weak hydrochloric acid for irrigation varied from 0.30 to $0.35 \mathrm{~kg} / \mathrm{s}$. The temperature of $313-323 \mathrm{~K}$ in the absorber was maintained by supplying cooled water. Fluctuations in the concentration of components in the inlet gas flow are respectively equal: for $\mathrm{HCl}-75.1-87.8 \%$ vol., For $\mathrm{Cl}_{2}-5.35-10.85 \%$ vol.

In parallel, portions of acid were sampled at the inlet and outlet, and then the density and temperature of the hydrochloric acid solutions were determined.

Based on the results of the experiment, two realizations of duration $T=1200 \mathrm{~min}$ were obtained for input $X(t)$ and output $Y(t)$ variables.

The impulse function $K(t)$ can be determined from the Wiener-Hopf equation [3, 4, 14]:

$$
R_{Y X}^{*}(\tau)=\int_{0}^{\infty} R_{X X}^{*}(t-\tau) K(t) \mathrm{d} t
$$

where $R_{X X}^{*}(t-\tau)$ and $R_{Y X}^{*}(\tau)$ are the estimates of the autocorrelation and cross-correlation functions. 
Correlation functions are determined by the following relationships [3, 4, 14]:

$$
\begin{aligned}
& R_{X X}^{*}(\tau)=\int_{0}^{T} X(t) X(t-\tau) \mathrm{d} t ; \\
& R_{Y X}^{*}(\tau)=\int_{0}^{T} Y(t) X(t-\tau) \mathrm{d} t .
\end{aligned}
$$

As a result of solving equations (1)-(3), provided that the random functions $R_{X X}^{*}(\tau)$ and $R_{Y X}^{*}(\tau)$ are stationary and ergodic, the function $K(t)$ is found.

At the stage of processing the experimental results, the following tasks are solved: centering the obtained realizations, calculating the estimates of the correlation functions $R_{X X}^{*}(\tau)$ and $R_{Y X}^{*}(\tau)$, determining the estimate of the object weight function $K^{*}(t)$.

The centering of the implementation is carried out according to the formula:

$$
\stackrel{0}{X}_{i}(t)=X_{i}(t)-M\{X(t)\},
$$

where

$$
M\{X(t)\}=\frac{1}{N} \sum_{i=1}^{N} X_{i}(t) .
$$

The ordinates of the estimates of the correlation functions are calculated by the formulas:

$$
\begin{aligned}
& R_{X X}^{*}(N)=\frac{1}{N-m+1} \sum_{i=1}^{N-m} \stackrel{0}{X}_{i}(t) \stackrel{0}{X}_{i}(t-m), \\
& R_{Y X}^{*}(N)=\frac{1}{N-m+1} \sum_{i=1}^{N-m} Y_{i}(t) \stackrel{0}{X}_{i}(t-m),
\end{aligned}
$$

where $m$ - the number of shifts of the output realization relative to the input one $(m \leq N / 4)$.

The final stage of research is the determination of the impulse function by solving the Wiener-Hopf equation using the obtained estimates of the correlation functions. There are a number of ways to solve the integral equation $[14,15]$. The most versatile is the algebraic method. Its essence lies in solving a system of algebraic equations obtained from equation (1) by replacing the integral with a finite sum:

$$
\frac{1}{T} R_{Y X}^{*}(\tau)=\sum_{i=0}^{N} K^{*}(i \Delta t) R_{X X}^{*}(\tau-i \Delta t)
$$

or in matrix form:

$$
[R]=[A] \times[K],
$$

where $[R]$ - a matrix-column of free members, whose elements are the values of the ordinates of the cross-correlation function $(t=0, T, 2 T, \ldots, m T) ;[A]$ - square symmetric matrix, the elements of which are the values of the ordinates of the autocorrelation function; $[K]$ - column matrix, whose elements are ordinates of the weight function:

$$
\left.\begin{array}{c}
\frac{1}{T} R_{Y X}(0) \\
\frac{1}{T} R_{Y X}(T) \\
\ldots \\
\frac{1}{T} R_{Y X}(m T)
\end{array}\right]=
$$

$$
\left[\begin{array}{cccc}
R_{X X}(0) & R_{X X}(T) & \ldots & R_{X X}[(m-1) T] \\
R_{X X}(T) & R_{X X}(0) & \ldots & R_{X X}[(m-2) T] \\
\ldots & \ldots & \ldots & \ldots \\
R_{X X}[(m-1) T] & R_{X X}[(m-2) T] & \ldots & R_{X X}(0)
\end{array}\right]\left[\begin{array}{c}
K(0) \\
K(T) \\
\ldots \\
K(m T)
\end{array}\right]
$$

The resulting system can be solved by the Gaussian method. For the correct solution of a system of algebraic equations, there is a need for special regularization methods $[3,4]$. The correctness of the solution of the system was achieved in the choice of the discretization step $\Delta t$ and the smoothing of the correlation functions with some analytical dependences. Calculations show that the correlation functions of industrial facilities are satisfactorily described by dependencies of the form [14]:

$$
R=A_{0} \exp \left(-\alpha_{0} t\right) \cos (w t) .
$$

The determination of the coefficients of the approximating curves is carried out using the method of averages, taking into account corrections.

The calculation of the estimates of the correlation functions $\stackrel{0}{X}(t)$ and $\stackrel{0}{Y}(t)$ from the obtained realizations $X(t)$ and $Y(t)$ was carried out according to relations (5), (6).

As a result, the ordinates of the estimates $R_{X X}^{*}$ and $R_{Y X}^{*}$, were obtained, which can be used to solve the matrix equation (9) obtained from the Wiener-Hopf equation.

All calculations were carried out in software environments MathCAD, Matlab.

\section{Research results and their discussion}

As noted above, the solution to eq. (7) in the general case is an ill-posed problem [15], that is, minor errors in the calculation of correlation functions can lead to significant errors in determining the impulse function. Therefore, the obtained correlation functions were approximated by dependences of the form (10). The approximation of the correlation functions led to the expressions:

$$
\begin{aligned}
\bar{R}_{X X} & =\exp (-0.03 t) \cos (0.1983 t), \\
\bar{R}_{Y X} & = \begin{cases}0.53 \exp (0.1892 t), & 0 \leq t<2, \\
0.74 \exp (-0.0055 t) \cos (0.0955 t), & t \geq 2 .\end{cases}
\end{aligned}
$$

The approximation error does not exceed $1 \%$.

The given expressions were used to calculate the ordinates $R_{X X}$ and $R_{Y X}$, by which the system of algebraic equations (9) was solved and the weight function $K(t)$ was obtained.

The found function $K(t)$ can be used to judge the hydrodynamic situation in the absorber. In calculations, however, it is more convenient to operate not with the distribution function itself, but with its probabilistic characteristics moments of different orders [16]. 
The coupling equations between the moments and the parameter characterizing the longitudinal mixing - the Peclet number $(\mathrm{Pe})$ - have the form [1, 17]:

$$
\begin{aligned}
& M_{2}=1+\frac{2\left(\mathrm{Pe}-1+e^{-\mathrm{Pe}}\right)}{\mathrm{Pe}^{2}}, \\
& M_{3}=1+\frac{6\left[\mathrm{Pe}(\mathrm{Pe}+1)-4+3 \mathrm{Pe} e^{-\mathrm{Pe}}+4 e^{-\mathrm{Pe}}\right]}{\mathrm{Pe}^{3}}, \\
& M_{4}= \\
& =\frac{12\left[\mathrm{Pe}^{3}+4 \mathrm{Pe}^{2}-28+\left(9 \mathrm{Pe}^{2}+30 \mathrm{Pe}+26\right) e^{-\mathrm{Pe}}+2 e^{-2 \mathrm{Pe}}\right]}{\mathrm{Pe}^{4}} .
\end{aligned}
$$

To calculate the number Pe, the moment $M_{2}$ was used, and with the help of the higher moments the adequacy of the chosen model was checked.

The moments of the distribution function were determined using the equations:

$$
\begin{aligned}
& M_{0}=\int_{0}^{\infty} K(t) \mathrm{d} t, \\
& M_{i}=t_{K} \int_{0}^{\infty} y(\theta) \theta^{i} d \theta, \quad i=1,2,3,4,
\end{aligned}
$$

where $\theta=t / t_{K}-$ dimensionless time; $y(\theta)=K(t) / M_{0}-\mathrm{di}$ mensionless estimate of $K(t)$.

Integrals (16), (17) for determining the moments were calculated by the Simpson method, equations (13), (14) were solved by dividing the interval in half. The calculation results are shown in Table 1 .

It was shown in $[16,17]$ that at $\mathrm{Pe}>30$ the flow structure is close to the displacement mode. The order of numbers $\mathrm{Pe} \approx 63$ obtained in experimental studies gives reason to believe that the hydrodynamics in the Korobon-KA absorber is satisfactorily described by the ideal displacement model (Table 1).

Tahle 1

Moments of the function $K(t)$ and Peclet numbers for the inlet-outlet channel of hydrogen chloride

\begin{tabular}{|c|c|c|}
\hline Moment order & Moment value $K(t)$ & Peclet criterion $(\mathrm{Pe})$ \\
\hline 1 & 0.999978 & - \\
\hline 2 & 1.031650 & 63.450 \\
\hline 3 & 1.394720 & 62.977 \\
\hline 4 & 1.829340 & 63.990 \\
\hline
\end{tabular}

Similar results were obtained for the hydrochloric acid inlet-outlet. $\mathrm{Pe} \approx 30$ values indicate a slight longitudinal mixing of the liquid in the absorber. However, the use of the perfect displacement model does not introduce significant errors in the results of mathematical modeling of this process, and in addition, greatly simplifies the calculation by the model.

\section{Conclusions}

An algorithm for studying the hydrodynamics of industrial absorbers based on normal operation data using random functions has been developed. This algorithm allows one to determine the hydrodynamic structure of flows during normal operation of the facility. The calculations are based on conducting an industrial experiment, processing experimental data, calculating estimates of autocorrelation and cross-correlation functions, and solving the Wiener-Hopf integral equation. A distinctive feature of the proposed technique is the study of the object in its normal operation mode.

To calculate the autocorrelation and cross-correlation functions, an experiment was carried out on an operating industrial installation. The experiment was carried out on an operating «Korobon-KA» type hydrogen chloride absorber during normal operation of the facility. The concentrations of hydrogen chloride and the resulting hydrochloric acid were determined at the absorber inlet and outlet, respectively. Based on the results of the experiment, two realizations of duration $T=1200 \mathrm{~min}$ were obtained for input $X(t)$ and output $Y(t)$ variables, sampling was performed every 90 seconds, the total number of experiments performed was 625 .

Estimates of correlation functions are calculated. The correlation functions are approximated by exponential dependences. The solution of the Wiener-Hopf equation in the form of a system of algebraic equations is obtained, the distribution function is obtained and its probabilistic characteristics are calculated - moments of different orders. The obtained values of the moments of various orders $(1-1.8)$ and the values of the Peclet criterion $(\mathrm{Pe} \approx 63)$ show the hydrodynamic conditions of ideal displacement for an absorber of the «Korobon-KA» type.

According to the results obtained, the proposed method for determining the hydrodynamic structure of flows will find application in the study of chemical-technological devices, when the object is exposed to random disturbances and the supply of a standard indicator is impossible due to violation of technological regulations.

\section{References}

1. Kafarov, V. V., Glebov, M. B. (2018). Matematicheskoe modelirovanie osnovnykh protsessov khimicheskikh proizvodstv. Moscow: Iurait, 403.

2. Bendat, J. S., Piersol, A. G. (2010). Random Data: Analysis and Measurement Procedures. Wiley, 640. doi: http://doi.org/ 10.1002/9781118032428

3. Volgin, V. V., Karimov, R. N. (1979). Otsenka korreliatsionnykh funktsii v promyshlennykh sistemakh upravleniia. Moscow: Energiia, 80.

4. Balakirev, V. S., Dudnikov, E. G., Tsirlin, A. M. (1967). Eksperimentalnoe opredelenie dinamicheskikh kharakteristik promyshlennykh obektov upravleniia. Moscow: Energiia, 232.

5. Vrentas, J. S., Vrentas, C. M. (2007). Axial conduction with boundary conditions of the mixed type. Chemical Engineering Science, 62 (12), 3104-3111. doi: http://doi.org/10.1016/ j.ces.2007.03.009

6. Vrentas, J. S., Vrentas, C. M. (2015). Dependence of Heat Transfer in a Circular Tube with Prescribed Wall Flux on Peclet Number and on Heating Length. Chemical Engineering Communications, 202 (7), 964-970. doi: http://doi.org/10.1080/ 00986445.2014 .883975

7. Lawrie, J. B., Abrahams, I. D. (2007). A brief historical perspective of the Wiener-Hopf technique. Journal of Engineering Mathematics, 59 (4), 351-358. doi: http://doi.org/10.1007/ s10665-007-9195-x

8. Cozzolino, D. (2014). The use of correlation, association and regression to analyse processes and products. Mathematical and Statistical Approaches in Food Science and Technology. Oxford, 19-30. doi: http://doi.org/10.1002/9781118434635.ch02

9. Kozub, D. J., Macgregor, J. F., Wright, J. D. (1987). Application of LQ and IMC controllers to a packed-bed reactor AICHE Journal, 33 (9), 1496-1507. doi: http://doi.org/10.1002/ aic.690330909 
10. Rakoczy, R., Masiuk, S., Kordas, M. (2010). Application of statistical analysis in the formulation of sewage treatment plant mathematical model. Inż. Ap. Chem., 49 (4), 64-65.

11. Sandrock, C., de Vaal, P. L. (2009). Dynamic simulation of Chemical Engineering systems using OpenModelica and CAPEOPEN. Computer Aided Chemical Engineering, 26, 859-864. doi: http://doi.org/10.1016/S1570-7946(09)70143-9

12. Bugaieva, L. M., Boiko, T. V., Beznosyk, Yu. O. (2017). Systemnyi analiz khimiko-tekhnolohichnykh kompleksiv. Kyiv: Interservis, 254

13. Khimicheskaia apparatura iz grafitovykh materialov: katalog spravochnik (2008). Sovmestnoe rossiisko-germanskoe predpriiatie OOO «Donkarb grafit».

14. Verlan, A. F., Sizikov, V. S. (1986). Integralnye uravneniia: metody, algoritmy, programmy. Kyiv: Naukova dumka, 543.

15. Tikhonov, A. N., Arsenin, V. Ia. (1979). Metody resheniia nekorrektnykh zadach. Moscow: Nauka, 285.
16. Golovanchikov, A. B., Dulkina, N. A. (2009). Modelirovanie struktury potokov v khimicheskikh reaktorakh. Volgograd: VolgGTU, 240.

17. Gelperin, N. I., Pebalk, V. L., Kostanian, A. E. (1977). Struktura potokov $i$ effektivnost kolonnykh apparatov khimicheskoi promyshlennosti. Moscow: Khimiia,

Yurii Beznosyk, PhD, Associate Professor, Department of Automation Hardware and Software, National Technical University of Ukraine «Igor Sikorsky Kyiv Polytechnic Institute», Kyiv, Ukraine, e-mail:yu_beznosyk@ukr.net, ORCID: http://orcid.org/0000-0001$7425-807 \bar{X}$

Liudmyla Bugaieva, PhD, Associate Professor, Department of Automation Hardware and Software, National Technical University of Ukraine «Igor Sikorsky Kyiv Polytechnic Institute», Kyiz, Ukraine,e-mail: bugaeva_l@ukr.net, ORCID: http://orcid.org/00000003-2576-6048 